\title{
More Time, Less Crime? Estimating the Incapacitative Effect of Sentence Enhancements
}

\author{
Emily G. Owens Cornell University
}

\begin{abstract}
Sentence enhancements may reduce crime both by deterring potential criminals and by incapacitating previous offenders, removing these possible recidivists from society for longer periods. I estimate the incapacitative effect of longer sentences by exploiting a 2001 change in Maryland's sentencing guidelines that reduced the sentences of 23-, 24-, and 25-year-olds with juvenile delinquent records by a mean of 222 days. I find that, during this sentence disenhancement, offenders were, on average, arrested for 2.8 criminal acts and were involved in 1.4-1.6 serious crimes per person during the period when they would have otherwise been incarcerated. Although my findings are significantly lower than previous estimates of incapacitation, I find that, on the margin, the social benefit of the crimes averted by incapacitation is slightly higher than the marginal cost to the state of imposing a 1-year sentence enhancement.
\end{abstract}

\section{Introduction}

Between 1984 and 2004, the number of people imprisoned in the United States grew from 682,000 to over 2.1 million, ${ }^{1}$ a 20 -year growth rate that was 10 times that of the U.S. population as a whole. Part of this growth can undoubtedly be attributed to an increase in the flow of people into the prison system-a trend driven by rising crime rates through the late 1980s and policies favoring incar-

I would like to thank Shawn Bushway, Mark Duggan, William Evans, Randi Hjalmarsson, Peter Reuter, Steven Raphael, John Shea, John Wallis, Stephanie Cellini, and an anonymous referee as well as seminar participants at University of North Carolina; Clemson University; California State University, Fullerton; Cornell University; University of Kansas; Mathematica Policy Research, Inc.; the Maryland Economics of Crime and Justice Policy Workshop; the National Institute of Justice and Southern Economic Association annual meetings; and the Association for Public Policy Analysis and Management (APPAM) fall conference for helpful advice and encouragement. In addition, I thank the Maryland State Commission on Criminal Sentencing Policy (MSCCSP), Washington County Department of Corrections, Prince George's County Department of Corrections, and Maryland Department of Public Safety and Correctional Services for allowing me to access administrative records and Richard Finci, David Soule and Charles Wellford for sharing their institutional knowledge. All views expressed, and errors, are my own.

${ }^{1}$ Bureau of Justice Statistics, Prison Statistics (http://www.ojp.usdoj.gov/bjs/prisons.htm).

[Journal of Law and Economics, vol. 52 (August 2009)]

(C) 2009 by The University of Chicago. All rights reserved. 0022-2186/2009/5203-0022 $\$ 10.00$ 
ceration over fines. Equally important, however, was a decrease in the outflow of inmates from the prison system back into society. Driving this trend was the widespread adoption of sentence enhancement policies designed to increase the severity of punishment by lengthening sentences and increasing incarceration time. Among the most popular sentence enhancement policies implemented over this period were mandatory minimum sentences, which obliged judges to adhere to strict minimum sentence lengths for certain crimes, and three-strikes laws, which required incarceration for repeat offenders.

In light of these patterns and policies and a remarkable drop in crime rates in the 1990s, a general consensus has emerged that the criminal justice system as a whole (including policing, sentencing, and incarceration) reduces the amount of crime in society (Doob and Webster 2003; Levitt 2001). However, concerns regarding the timing and the application of sentence enhancement policies, as well as the confounding effects of other policy changes in the justice system, have resulted in little consensus on how changes in sentencing have contributed to reductions in criminal activity. ${ }^{2}$ The relationship between incarceration and crime rates is further complicated because incarceration theoretically has two distinct effects on individual criminal behavior: deterrence and incapacitation. A deterred offender is able to commit crime but chooses not to, whereas an incapacitated offender would choose to commit crime but is unable to do so. The relative contribution of these factors to the decline in crime has important fiscal implications for governments.

If the threat of longer sentences deters criminal behavior, the state does not have to increase spending on arrest, prosecution, and incarceration. Although this outcome is promising, empirical evidence of a deterrent effect is mixed at best $^{3}$ and must be weighed against the ability of other social programs to alter behavior. ${ }^{4}$ In the case of incapacitation, on the other hand, the government must make a nontrivial fiscal outlay on prison construction and inmate supervision, ${ }^{5}$ and longer periods of incarceration may impose nontrivial costs on family members, health, and labor market opportunities for the offenders. ${ }^{6}$

\footnotetext{
${ }^{2}$ For extensive and critical reviews of research on incapacitation and deterrence, see Zimring and Hawkins (1995), Spelman (2000), Doob and Webster (2003), and Levitt (2001).

${ }^{3}$ Reviews of the literature by Nagin (1998), Levitt (2001), and Doob and Webster (2003) highlight the contentious nature of the debate over sentence enhancements and deterrence. Becker (1968) suggests that rational criminals would be deterred by harsher punishments, but Lee and McCrary (2006) demonstrate how high discount rates result in rational criminals being undeterred by increased sanctions.

${ }^{4}$ Donohue and Siegelman (1998), for example, suggest that early childhood interventions are at least as cost-effective as increased incarceration in reducing crime.

${ }^{5}$ Greenwood et al. (1996) estimate that the effect of California's three-strikes law on the prison population could cost the state $\$ 5.5$ billion per year.

${ }^{6}$ This observation follows from the Becker (1971) model of discrimination. Pager (2003) finds evidence of negative effects of incarceration on future employment of a magnitude similar to those for racial discrimination. Recent work by Oliver et al. (2006) highlights the link between black male imprisonment and black child poverty. Recent work by Johnson and Raphael (2009) suggests that the high incarceration rates among black Americans can explain a large fraction of racial disparities in HIV infection.
} 
This paper seeks to untangle the relationship between sentence length and crime, isolating the incapacitative effect of sentence enhancements and weighing the fiscal costs and social benefits of such policies. Early studies of incapacitation characterize the effect as removing a "slice" of a criminal career (Shinnar and Shinnar 1975; Blumstein 1983), potentially reducing crime as offenders are prevented from reentering society. The number of crimes prevented through incapacitation by a sentence enhancement equals the number of crimes incarcerated offenders would have committed if they were on the streets during that enhancement. The empirical task is to create a plausible estimate of this number. Self-reports of criminal behavior immediately prior to incarceration, ${ }^{7}$ which Zimring and Hawkins (1995) characterize as the "window period," have produced estimates of incapacitation that range from 187 crimes prevented per prisoner-year (Zedlewski 1987) to 12 or fewer such crimes (DiIulio and Piehl 1991, 1995). Setting aside the wide range of these estimates, it is unclear that the potential criminal behavior of the average incarcerated inmate is the relevant metric when thinking about longer sentences. Sentence enhancements increase the incapacitation only of inmates who are about to be released, and the stock of incarcerated offenders is likely to be significantly more criminal than the exiting flow from that population (see Donohue and Siegelman 1998; Cavanagh and Kleiman 1990). ${ }^{8}$ Existing literature has generated estimates of an average effect: how many crimes does incarceration prevent? This paper estimates a marginal effect: how many crimes are prevented by longer periods of incarceration? Finally, the cited studies rely on data collected before 2000, and the large decline in aggregate crime rates during the late 1990s casts doubt on the applicability of past estimates of incapacitation to current policy. ${ }^{9}$

An ideal way to estimate the effect of sentence enhancements on crime would be to randomly assign offenders to short and long prison sentences. In that case, the average criminal behavior of the "lucky" offenders receiving the shorter sentences can be interpreted as the criminal activity the "unlucky" offenders were prevented from engaging in during their sentence enhancement. Once the unlucky offenders are released, the difference between their criminal behavior and the contemporaneous criminal behavior of the lucky offenders provides insight on the effect of sentence length on criminal behavior.

I approximate this ideal experiment using quasi-experimental variation in

${ }^{7}$ This approach, used by Zedlewski (1987), DiIulio and Piehl (1991, 1995), and Cohen (1983) is based on the model of incapacitation and the criminal career developed in Avi-Itzhak and Shinnar (1973) and Shinnar and Shinnar (1975). Recent research by Bhati (2007) builds on these models using information theory to model hypothetical criminal behavior over the life course.

${ }^{8}$ If offenders tend to be incarcerated after pronounced increases in their rate of criminal behavior (Zimring and Hawkins 1995), this upward bias is exacerbated.

${ }^{9}$ Johnson and Raphael (2007) develop a model of incarceration and crime rates that allows them to separate exogenous and endogenous changes in the two over time. They then apply their model to crime and incarceration data from before and after 1990 and find that the implied elasticity of crime with respect to prison beds has fallen by as much as 70 percent. Research on adolescent incapacitation by Sweeten and Apel (2007) also finds that the potential benefits of incapacitation may have fallen over time as well. 
sentence length created by a change in Maryland law that reduced the recommended sentences for a specific group of individuals 23-25 years old. In Maryland, a recommended sentence is calculated for each convicted offender on the basis of his criminal history and the crime for which he is convicted using a point system developed by the Maryland State Commission on Criminal Sentencing Policy (MSCCSP). On July 1, 2001, a policy change reduced the age at which an offender's juvenile record was excluded from the criminal history, from 26 to 23 years. After controlling for characteristics of the offender and crime, I find that each additional juvenile delinquent point officially assigned to an offender increased incarceration length by a mean of 222 days.

After observing the number of delinquent points offenders sentenced after July 1, 2001, would have qualified for under the prior regime, I then estimate the additional days of incarceration that offenders with juvenile histories would have received if they had been sentenced under the old guidelines. Under the assumption that the change in sentencing is unrelated to changes in underlying criminality, the offense rate-or number of crimes per year-of the lucky former delinquents in this postrelease window serves as the counterfactual for the number of crimes that the unlucky 23-25-year-olds would have committed if they had been released early.

I find that offenders are arrested at a mean rate of 2.8 times per year and are involved in approximately 1.5 index crimes (murder, manslaughter, assault, robbery, rape, car theft, burglary, and larceny) per year during the period when they would have otherwise been incarcerated. A back-of-the-envelope costbenefit analysis suggests that, although the marginal benefit of incapacitation is significantly smaller than the average effect, the social benefit does outweigh the marginal cost of incarcerating a prisoner for an additional year.

The paper proceeds as follows: In the first section, I describe the Maryland sentencing process and the 2001 law change in detail. A discussion of the data set I use and the econometric model follows. In Section 4, I present my estimates of the number of crimes that sentence enhancements prevent by incapacitation. I discuss the costs associated with sentence enhancements in Section 5 and offer a concluding discussion in Section 6.

\section{Sentencing in Maryland}

Maryland is one of 25 states in which guidelines are used to determine the sentence of a convicted offender. ${ }^{10}$ An adult convicted of a crime in a Maryland circuit court is assigned two numeric scores-one characterizing the offense and the other the offender. These scores and a corresponding range of recommended sentences are given to the judge prior to sentencing. The midpoint of this range is highly correlated with sentence length $(\rho=.6)$, and although judges are not

${ }^{10}$ This count includes the District of Columbia. 
penalized for deviating, roughly half of sentences fall within this range. ${ }^{11}$ Moreover, these scores and sentencing guidelines further influence an inmate's actual time served because they are later used by parole boards in deciding whether to release an incarcerated offender.

Although the offense scores identify the type and severity of the crime committed, the offender score is most relevant in assessing the group affected by the change in law examined in this paper. This score is calculated as the sum of four elements - the individual's adult criminal history, juvenile criminal history, history of parole violations, and relationship to the criminal justice system at the time of the offense-with a maximum score of 9. Most important to my identification strategy is the assignment of delinquent points to this score. Before the change in law, an offender who was younger than 26 and who had committed a previous crime as a juvenile could receive up to 2 delinquent points, with each point resulting in a longer recommended sentence. ${ }^{12}$ To the extent that parole boards took sentences and delinquent points into account, 23-, 24-, and 25year-olds with juvenile histories potentially received significant reductions in incapacitation.

In 1998, the MSCCSP became concerned that their treatment of adults with juvenile histories was too harsh relative to that in other states. ${ }^{13}$ To rectify this inequity, the commission determined that delinquent points would be assigned only to offenders aged 22 years or younger at the time of offense. The revised guidelines, in which offenders aged out of their juvenile histories at 23 instead of 26 years, went into effect on July 1, 2001. This meant that 23-, 24-, and 25year-old offenders who would have had delinquent points added to their offender score before July 1, 2001, instead received 0 points thereafter.

How does the recommended sentence translate to actual sentence length and time served? The average effect on the amount of time served by $23-25$-yearolds is shown in Figure 1. The null hypothesis that nondelinquents and former delinquents were incarcerated for equivalent amounts of time is easily rejected under the old guidelines $(t=-5.04)$ but not under the new guidelines $(t=$ -.85 ). The policy-relevant window of free time during which I measure incapacitation is the number of extra days of incarceration lucky former delinquents would have received if sentenced under the old guidelines.

\footnotetext{
${ }^{11}$ Annual reports by the MSCCSP indicate that, between 1999 and 2002, roughly 50 percent of imposed sentences fell within the recommended range. Since 2002, the percentage of sentences that fall within this range has been above 70 percent.

${ }^{12}$ One delinquent point was assigned if the offender had two or more past findings of juvenile delinquency or one confinement and had not remained crime free for more than 5 years. A record of multiple confinements resulted in 2 delinquent points being added to the offender score.

${ }^{13}$ As noted by Dr. Charles Wellford, MSCCSP member and former chair, telephone conversation with the author, October 2005.
} 


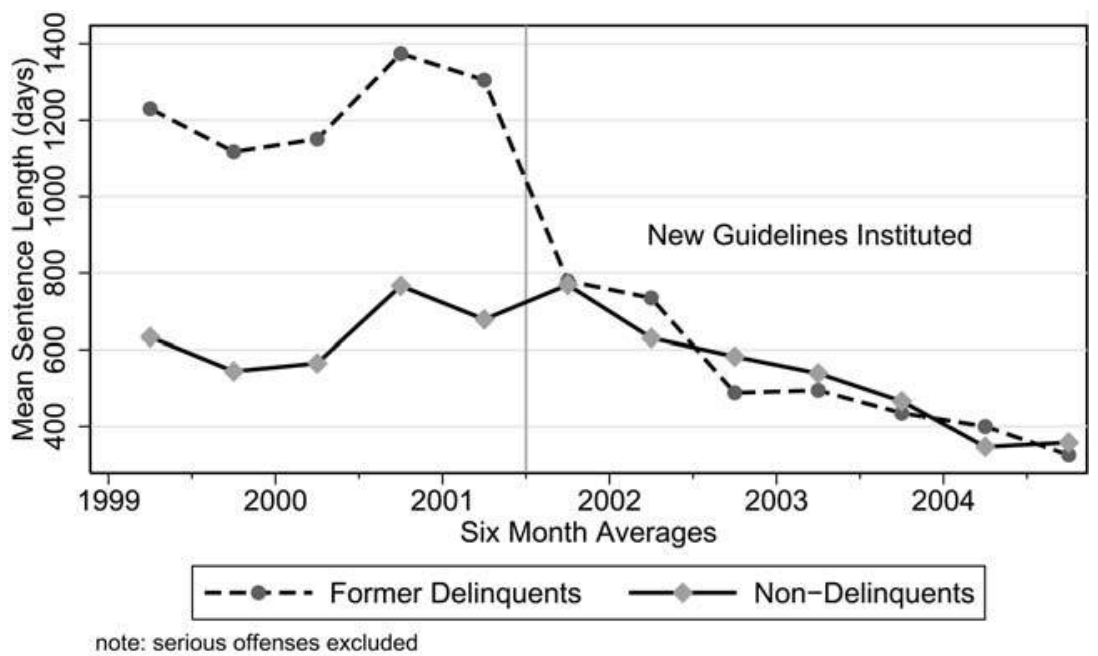

Figure 1. Average incarceration spells of all 23-25-year-old males by delinquent status

\section{Data and Econometric Approach}

\subsection{Data Description}

I use data from the MSCCSP on 3,345 sentences of males between the ages of 23 and 25 who were sentenced between 1999 and 2004. Each observation includes the name, race, and date of birth of the convicted offender as well as information on the elements of his offender and offense scores, the jurisdiction in which he was sentenced, and the date he was sentenced. I identify the number of delinquent points a 23-25-year-old sentenced after July 1, 2001, would have received under the old regime using his prior convictions in Maryland circuit court.

The goal of this paper is to estimate the number of crimes averted per year of additional incarceration. The relevant denominator is time served, not sentence length. To obtain time served, the sentencing data are linked to incarceration data from the administrative records of the Anne Arundel, Prince George's, and Washington Counties' Departments of Corrections and the Maryland Department of Public Safety and Correctional Services, which oversees the Baltimore City jails and Maryland state prisons. Approximately 39 percent of Maryland residents lived in one of these jurisdiction in $2000,{ }^{14}$ and 64 percent of convictions between 1999 and 2004 occurred in one of these four jurisdictions.

I proxy for the number of crimes averted with the number of arrests accumulated by lucky delinquents when they would have otherwise been incarcerated.

${ }^{14}$ U.S. Census Bureau, State and County Quick Facts: Maryland (http://quickfacts.census.gov/qfd/ states/24/24510.html). 
Table 1

Characteristics of 23-25-Year-Old Offenders Sentenced in Maryland, 1999-2004

\begin{tabular}{|c|c|c|c|c|}
\hline \multirow[b]{3}{*}{ Total days served } & \multicolumn{2}{|c|}{ Old Guidelines } & \multicolumn{2}{|c|}{ New Guidelines } \\
\hline & Nondelinquent & Delinquent & \multirow{2}{*}{$\frac{\text { Nondelinquent }}{510(549)}$} & \multirow{2}{*}{$\frac{\text { Delinquent }}{471(489)}$} \\
\hline & $687(818)$ & $1,274 \quad(920)$ & & \\
\hline Sentence length ${ }^{\mathrm{a}}$ & $37.2(56.2)$ & $96.2(100)$ & $45.1(84.3)$ & $50.4(69.8)$ \\
\hline Incarcerated (\%) & 76.9 & 93.8 & 74.5 & 78.9 \\
\hline Not released (\%) & 15.1 & 35.0 & 26.9 & 24.1 \\
\hline Total charges & $1.40 \quad(.94)$ & 1.98 (1.79) & $1.54(1.41)$ & $1.96(3.83)$ \\
\hline 2nd Sentence (\%) & 2.0 & 4.1 & 1.8 & 2.2 \\
\hline \multicolumn{5}{|c|}{ Worst offense type (\%): } \\
\hline Drug & 64.0 & 42.3 & 61.2 & 68.4 \\
\hline Violent & 27.6 & 38.1 & 28.8 & 23.3 \\
\hline Property & 8.2 & 19.6 & 9.2 & 8.3 \\
\hline VOP & .2 & .0 & .8 & .0 \\
\hline Worst offense score & $5.23(2.19)$ & $(2.64)$ & $4.92(2.14)$ & $5.00(2.29)$ \\
\hline Delinquent points & N.A. & $(.45)$ & N.A. & $1.27(.44)$ \\
\hline \multicolumn{5}{|l|}{ Nondelinquent } \\
\hline offender score & $3.16(2.30)$ & $(1.79)$ & $3.36(2.14)$ & $4.48(2.20)$ \\
\hline Age at offense & $24.0 \quad(.81)$ & $(.75)$ & $23.9 \quad(.82)$ & $23.6 \quad(.77)$ \\
\hline Black (\%) & 83.9 & 76.3 & 81.4 & 80.4 \\
\hline Sentences & 1,179 & 97 & 1,940 & 133 \\
\hline
\end{tabular}

Note. Standard deviations are in parentheses. VOP $=$ violation of parole; N.A. $=$ not applicable.

a Sentence length is reported in months, with 101 serious offenses excluded.

The Maryland Arrest Repository data, or rap sheet data, obtained from the Maryland Department of Public Safety and Correctional Services record every arrest made by a law enforcement agency in Maryland and track individuals using a fingerprint-supported state identification number. The rap sheet data allow me to add information on dates of arrest, reasons for arrest, and arresting agency for each individual who has a Maryland arrest record through January $5,2006 .{ }^{15}$

Table 1 compares the race, offense scores, offense types, and observed incarceration spells of former delinquents and nondelinquents in my sample. Unlucky former delinquents appear to have spent almost 2 additional years incarcerated relative to offenders without delinquent records, whereas lucky offenders appear to serve slightly less time, if any, than nondelinquents overall. Comparing mean observed time served is potentially misleading because right censoring (namely, of incomplete incarceration spells) creates an upper bound on the difference between sentences of lucky delinquents and nondelinquents who are sentenced toward the end of the observed time frame. An alternative way to illustrate the changing effect of delinquent points on incarceration is to compare the mean sentence passed down by a judge. The second row of Table 1 presents mean

\footnotetext{
${ }^{15}$ Creating a complete set of sentence, intake, release, and arrest dates requires that I exclude a nontrivial fraction of my affected sample. Table A1 describes the characteristics of 2,502 convictions that are excluded from the sample. For a detailed discussion of the excluded and included cases, see Owens (2007, pp. 90-147).
} 
sentences passed down by judges. Former delinquents sentenced under the old guidelines received sentences of 96 months on average, compared with 37-month sentences given to nondelinquents. Under the new guidelines, former delinquents received sentences of 50 months on average, only 5 months more than nondelinquents.

Former delinquents sentenced under the new guidelines were much more likely (68 percent versus 42 percent) to be convicted of drug offenses than were those convicted under the old guidelines. ${ }^{16}$ There are two reasons for this. I am more likely to be able to identify drug offenders as former delinquents if drug offenders move in and out of the legal system at a higher frequency than other types of offenders. Alternately, if prosecutors see drug offenders as less dangerous than those convicted of violent or property offenses, they may be less likely to assign these particular offenders official delinquent enhancements. ${ }^{17}$ This is potentially an area of concern if there is heterogeneity in the effect of the delinquent enhancement on sentence length across offense types. In Table A2, I examine this possibility. In this particular sample, I find no compelling evidence of a heterogeneous effect. In all other respects, the demographic characteristics of the four groups are generally similar.

It is possible that the sentence disenhancement that delinquent 23-25-yearolds received after July 1, 2001, induced some of those delinquents to commit crime. By lowering the severity of the punishment they would receive, 23-25year-olds with delinquent records who may have chosen not to commit crimes prior to July 1,2001 , may have done so once the new guidelines were in place. ${ }^{18}$ If this were the case, lucky former delinquents would be, on average, less criminal than unlucky former delinquents, and I cannot reject the null hypothesis that the adult criminal histories are constant over time. This specific policy change was not publicized, and a Lexis-Nexis search of major and local Maryland newspapers between 1998 and 2004 found no mention of this change in the guidelines.

\subsection{Econometric Approach}

To estimate how many crimes could have been prevented by the juvenile sentence enhancement, it is necessary to know how long a lucky delinquent would have been incarcerated in the absence of the rule change. I use a differencein-difference approach, comparing the change in time served for former delinquents to the change for nondelinquents, whose sentences are independent of how delinquent points are calculated. ${ }^{19}$ As shown in Table 2, on average, former

\footnotetext{
${ }^{16}$ This pattern is not evident in former delinquents between 20 and 22 years old.

${ }^{17}$ This is similar to the phenomenon of diagnosis-related-group creep identified by Simborg (1981).

${ }^{18}$ This is a logical extension of the Becker (1968) model of criminal behavior.

${ }^{19}$ Several other changes in the guidelines went into effect on July 1, 2001, including a change in the penalty for crimes against the elderly and the inclusion of victim information in the worksheet. As long as these additional changes affected former delinquents and nondelinquents equally, this should not bias my estimate. This assumption can be verified by examining the effect of the change in the guidelines on the sentences of males in different age groups.
} 
Table 2

Sentence Length and Time Served (in Months) for 20-25-Year-Olds Over Time

\begin{tabular}{|c|c|c|c|c|c|}
\hline & \multicolumn{2}{|c|}{ Sentence Length } & \multicolumn{2}{|c|}{ Time Served } & \multirow[b]{2}{*}{ Difference } \\
\hline & $\begin{array}{c}\text { Old } \\
\text { Guidelines }\end{array}$ & $\begin{array}{c}\text { New } \\
\text { Guidelines }\end{array}$ & $\begin{array}{c}\text { Old } \\
\text { Guidelines }\end{array}$ & $\begin{array}{c}\text { New } \\
\text { Guidelines }\end{array}$ & \\
\hline \multicolumn{6}{|l|}{ 23-25-Year-olds: } \\
\hline Nondelinquent $(N=3,119)$ & $46.4 \quad(3.19)$ & $(3.39)$ & $23.2 \quad(.803)$ & $17.9 \quad(.435)$ & $-5.27 \quad(.839)$ \\
\hline 1 Point $(N=167)$ & $97.4(14.2)$ & $63.4 \quad(12.7)$ & $42.9(3.67)$ & $15.6(1.63)$ & $-27.2 \quad(3.66)$ \\
\hline 2 Points $(N=63)$ & $150.8(60.5)$ & $380.1(242)$ & $45.9(5.94)$ & $19.1(3.24)$ & $-26.8 \quad(6.36)$ \\
\hline \multicolumn{6}{|l|}{ 20-22-Year-olds: } \\
\hline Nondelinquent $(N=3,984)$ & $41.1 \quad(2.88)$ & $(2.22)$ & $22.4 \quad(.703)$ & $14.5(.350)$ & $-7.86 \quad(.709)$ \\
\hline 1 Point $(N=723)$ & $77.4 \quad(8.77)$ & $97.6 \quad(17.7)$ & $32.1(1.85)$ & $22.9 \quad(.904)$ & $-9.24(1.84)$ \\
\hline 2 Points $(N=241)$ & $94.4(24.8)$ & $(14.5)$ & $38.0(2.95)$ & $29.7(1.59)$ & $-8.30(3.12)$ \\
\hline
\end{tabular}

Note. Standard errors are in parentheses. The sample includes outliers.

delinquents with 1 delinquent point received sentences of 97.4 months $(\mathrm{SE}=$ 14.2 ) if sentenced under the old guidelines, compared with 63.4 months ( $\mathrm{SE}=$ 12.7) afterward. These different sentences resulted in an average reduction in time served of 23.4 months ( $\mathrm{SE}=3.52$ ), or about 702 days per delinquent point. ${ }^{20}$ In comparison, 23-25-year-olds without delinquent records were incarcerated for 23.2 months $(\mathrm{SE}=.80$ ) prior to July 1,2001 , and 17.9 months (SE $=.435)$ after that date. A basic comparison of means suggests that, on average, lucky former delinquents would have spent an additional 544 days in prison for each delinquent point in their record if they had been subject to the old guidelines.

In an interesting falsification test of this effect, I see no such pattern for convicted males between the ages of 20 and 22 . There is no statistically or substantively significant difference in the periods of incarceration for former delinquents over time that is not explained by changes in punishment for nondelinquents. This finding supports the argument that the reduction in time served for 23-, 24-, and 25-year-old former delinquents was due to this specific sentence disenhancement rather than some other consistent pattern placing greater emphasis on age or less emphasis on offender scores in sentencing and parole decisions.

Assuming that each lucky delinquent would have been released 544 days later under the old guidelines requires assumptions that would make incapacitation estimates unbelievable. Close inspection of Tables 1 and 2 substantiates two primary sources of concern. First, there are observable dimensions on which former delinquents vary over time. The top 95th percentile of convicted counts for 23-25-year-olds with 2 delinquent points increases from four to over 15 after July 1, 2001. As a result, the average sentence length appears to increase over time for this group. A simple test of difference in means also does not account

${ }^{20}$ This figure is calculated as the weighted average reduction per point for 23-25-year-old delinquents in Table 2. 


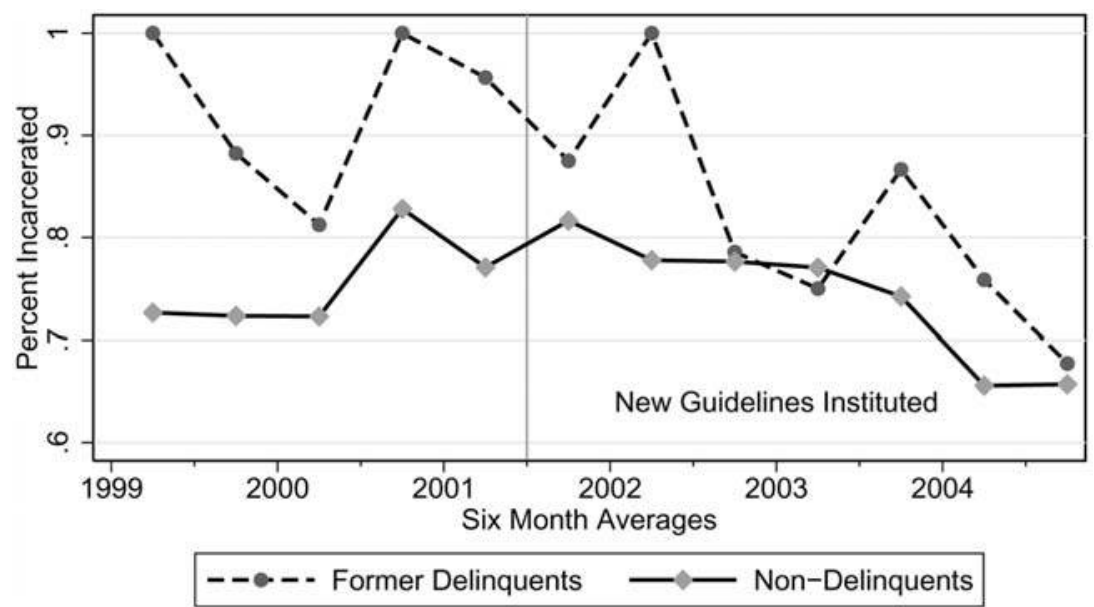

note: serious offenses excluded

Figure 2. Percentage of convicted 23-25-year-old males incarcerated by delinquent status

for the fact that 766 of these sentences are incomplete at the time of observation, which means that I do not observe the total amount of time served in each case. In particular, the largest possible value of observed time served is smaller for individuals sentenced after July 1 than before.

Comparing mean time served also requires the assumption that delinquent points equally affected the probability and length of incarceration. When the average time served in Figure 1 is distilled into Figures 2 and 3, it is evident that changes in the intensive margin (Figure 3) are driving the break in trend at the date of the guideline. This is an intuitive result: someone convicted of murder will be incarcerated even if it is the first offense, whereas someone convicted of possession of drug paraphernalia will typically not be incarcerated for that offense, even if he has a long criminal record. ${ }^{21}$

To obtain a more accurate estimate of the additional amount of time a lucky former delinquent would have been incarcerated, I use a two-step estimation procedure. First, I model the extensive margin (Figure 2), the probability of being incapacitated for any period of time, using a probit model, where the dependent variable equals one if Sentence ${ }_{i}$ results in any period of incarceration:

$$
\begin{aligned}
P\left(S_{i}^{\star}>0 \mid X_{i}\right)= & \Phi\left[\varpi+\beta^{\mathrm{P}} \text { Facts }_{i}^{\mathrm{P}}+\alpha_{\mathrm{OG}} \text { OldGuide }_{i}+\alpha_{\mathrm{D}} D_{i}\right. \\
& \left.+\alpha_{\mathrm{OGD}}\left(\text { OldGuide }_{i} \times D_{i}\right)\right] .
\end{aligned}
$$

${ }^{21}$ DiIulio (1996) points out that the most controversial aspect of California's three-strikes law was the increased weight of an individual's criminal history over the immediate offense in determining whether to incarcerate someone. 


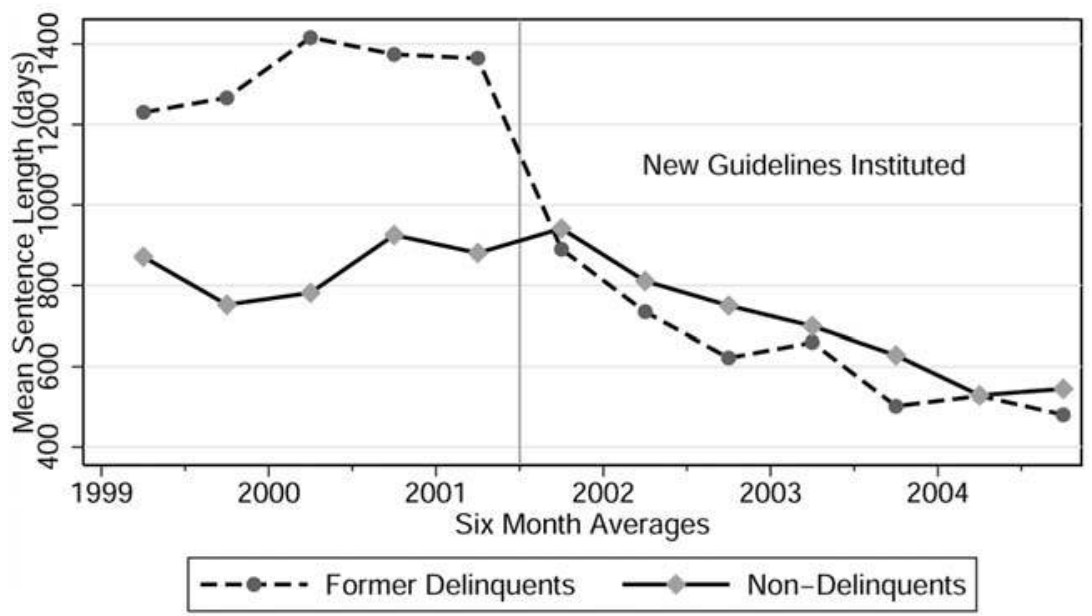

note: serious offenses excluded

Figure 3. Average incarceration spells of incarcerated 23-25-year-old males by delinquent status.

I control for the facts of the case, Facts ${ }_{i}^{\mathrm{P}}$, which include the offender score minus any delinquent points, the offense scores of the three most serious offenses, and the total number of criminal acts for which the offender is convicted. I also control for whether the offender is black, whether the offender is later convicted of an additional offense (that could have occurred at any time) while serving the current sentence, and the offender's age at the time of the most serious offense. Because the offense scores of drug, property, and violent offenses are calculated differently, I allow the effect of the offense score to vary with offense type, and I adjust the standard errors in my model to allow for unobserved correlation in incarceration length over time for offenses of the same type within a jurisdiction. The estimated values of $\alpha_{\mathrm{OG}}, \alpha_{\mathrm{D}}$, and $\alpha_{\mathrm{OGD}}$ represent the change in probability of incarceration associated with delinquent status $D_{i}$, being sentenced under the old guidelines OldGuide $_{i}$, and having delinquent points included in the offender score.

Turning to changes in incarceration on the intensive margin (Figure 2), I restrict my attention to convictions in which an offender was incapacitated for at least 1 day. ${ }^{22}$ I assume that, for all convictions that result in incarceration,

${ }^{22}$ This includes pretrial detention. I am not able to determine whether an individual received credit for pretrial detention at sentencing and therefore assume that it was always awarded. 
actual sentence length $S_{i}^{*}$ (measured in days) follows a negative binomial distribution, with

$$
P\left(S_{i}^{*}=y\right)=\frac{\Gamma(\delta+y)}{\Gamma(y+1) \Gamma(\delta)}\left(\frac{\delta}{\delta+\lambda_{i}}\right)^{\delta}\left(\frac{\lambda_{i}}{\delta+\lambda_{i}}\right)^{y},
$$

where

$$
\begin{aligned}
\lambda_{i}= & \exp \left[\omega+\beta^{\mathrm{N}} \text { Facts }_{i}^{\mathrm{N}}+\theta_{\mathrm{OG} \text { OldGuide }_{i}+\theta_{\mathrm{D}} D_{i}}\right. \\
& \left.+\theta_{\mathrm{OGD}}\left(\text { OldGuide }_{i} \times D_{i}\right)+\varepsilon_{i}\right] .
\end{aligned}
$$

I model the actual incarceration spell, $S_{i}^{\star}$, of male 23-25-year-olds in Maryland as a function of the facts of the case, Facts ${ }_{i}^{\mathrm{N}}$; a dummy variable, OldGuide ${ }_{i}$, that equals one if the sentence took place under the old guidelines regime; the total delinquent points, $D_{i}$, that the offender would qualify for if the guidelines had not been revised; and the interaction of total delinquent points and being sentenced under the old guidelines. Because additional unobserved factors may be related to both my observed characteristics and sentence length, in this specification I include in Facts ${ }_{i}^{\mathrm{N}}$ dummy variables for the jurisdiction of sentence, which control for time-invariant differences in judicial and policing practices across counties, and either a set of biannual dummy variable ${ }^{23}$ or jurisdictionspecific time trends, which control for statewide changes over time that may affect sentencing, such as political pressure (circuit court judges are elected every 2 years), prison overcrowding, or statewide changes in police tactics. ${ }^{24}$

I estimate the parameters of this equation by maximizing an adjusted negative binomial likelihood function, where I account for the difference in $S_{i}^{*}$, the actual amount of incarceration associated with Sentence ${ }_{i}$, and $S_{i}^{\mathrm{C}}$, the length of time I observe someone spending in prison or jail. I then use the estimated values of $\alpha_{\mathrm{OG}}, \alpha_{\mathrm{D}}, \alpha_{\mathrm{OGD}}, \theta_{\mathrm{OG}}, \theta_{\mathrm{D}}$, and $\theta_{\mathrm{OGD}}$ from these two equations to predict the additional amount of incarceration each delinquent point caused, allowing for a heterogeneous affect of delinquent points on extensive and intensive margins. ${ }^{25}$

My primary estimation results from equations (1) and (3), as well as tests of my modeling assumptions, are presented in Table 3. I find that the potential sentence enhancement per delinquent point ranged from 10 to 1,319 days, with

\footnotetext{
${ }^{23}$ In a linear model, the difference-in-difference estimator, which is marginal effect of interest, is completely captured in the coefficient on the interaction term. In a nonlinear model such as this one, the first-order effects do not completely drop out of the marginal effect and, therefore, must be identified. To be able to identify any first-order effect of being sentenced under the old guidelines, in the fixed-effects model I drop both biannual dummy variables for 2001. See Ai and Norton (2003).

${ }^{24}$ Because I have complete sets of time served for a subset of jurisdictions, jurisdiction-specific effects are perfect predictors of incarceration in equation (1). For example, while I observe convictions that resulted in no time served in Prince George's County, I observe time served in Montgomery County only for convictions that resulted in a sentence of 12 months or longer.

${ }^{25} \mathrm{~A}$ detailed discussion of my estimation procedure is included in the Appendix.
} 


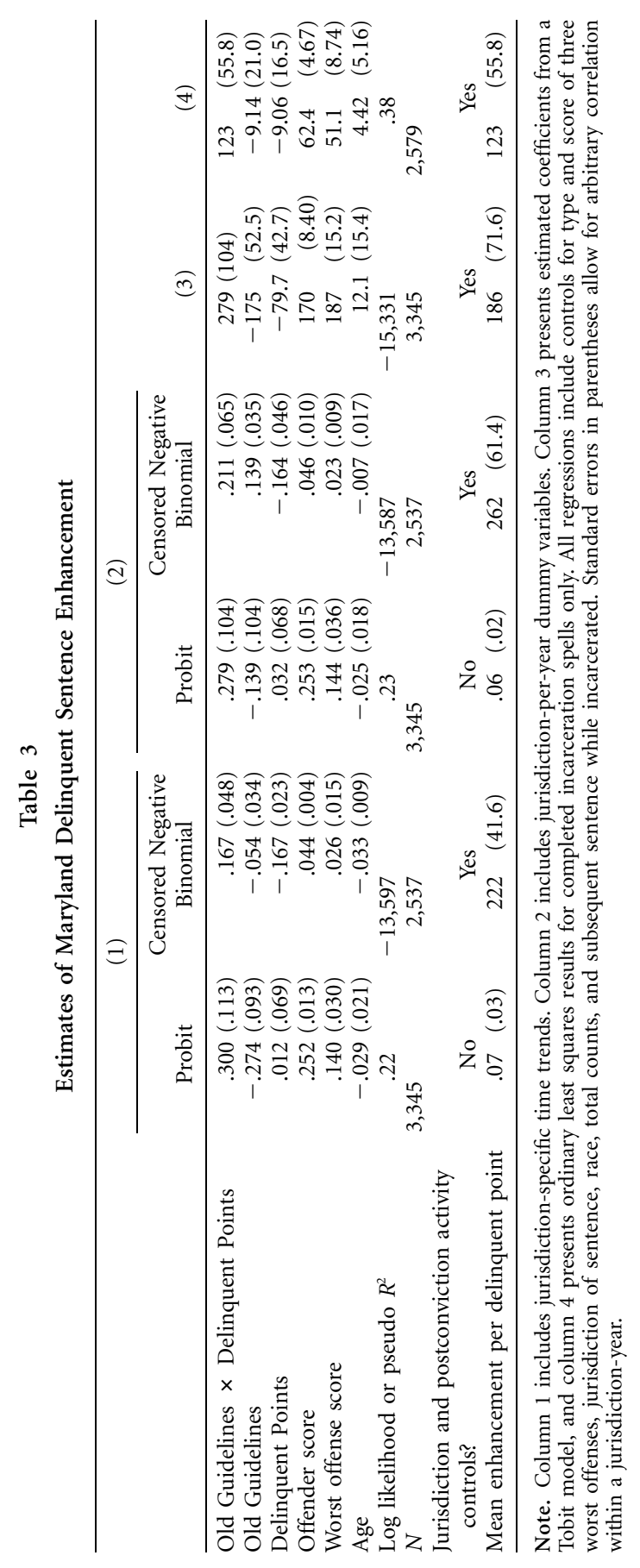


a mean possible enhancement of 222 days $\left(\mathrm{SE}=41.6\right.$ days) ${ }^{26}$ Note that this estimate is statistically robust to alternate specifications-6-month fixed effects instead of time trends, using a censored Tobit model instead of my two-step procedure, and restricting my attention only to completed periods of incarceration. Instead of following each offender for a fixed amount of time before or after incarceration, I now have a policy-relevant period of time, a postrelease window with which to estimate the incapacitative effect of sentence enhancements. Any crime committed by a convicted offender during this postrelease window period is an offense that would have been prevented by incapacitation under the old sentencing guidelines.

\subsection{Estimating the Incapacitative Effect}

I use a two-part decision rule for selecting the final sample of 23-25-yearolds. First, the offender must serve at least 1 day in jail or prison. Second, I must observe the offender when he is released. This decision rule limits my sample to 133 of 230 delinquent 23-25-year-olds, 73 of whom were sentenced after 2001. ${ }^{27}$ Table 4 compares characteristics of the lucky and unlucky former delinquents who were incarcerated and released. In terms of offender and worst offense scores, there does not appear to be a substantial difference between the lucky and unlucky delinquents who are released, and I cannot reject the null hypothesis that the prior records of these two groups of offenders are equal $(t=.78)$. The postrelease criminal behavior of lucky offenders can therefore be used as a reasonable estimate of the crimes unlucky offenders would have committed had their juvenile history not been a factor at sentencing.

Using the estimated sentence enhancement that lucky delinquents would have received under the old guidelines, I calculate a hypothetical late release date for each of the 73 former delinquents. On the basis of my regression results, I estimate possible sentence enhancements ranging from 75 to 302 days per delinquent point. I refine the length of each postrelease window of these 73 former delinquents, adjusting it to equal the difference between their hypothetical release date and actual release date, subtracting any time they spent reincarcerated during that period. Taking reincarceration into account, these offenders spent an average of 164 free days on the street when they would have been incarcerated under the old guidelines, with the shortest potential free period being 1 day and the longest slightly over 1 year. I observe the number of arrests each of these individuals accumulates during his postrelease window and divide the number of arrests by the number of days he was at risk of committing a crime. Multiplying this daily arrest rate by 365 gives me an annual arrest rate.

For many reasons, arrest rates do not necessarily correspond with actual of-

${ }^{26} \mathrm{I}$ adjust my standard errors to allow for arbitrary correlation in time served for violent, property, and drug convictions within a jurisdiction in any 6-month interval.

${ }^{27}$ Twenty-eight of 133 sentences of lucky former delinquents do not result in incarceration, and an additional 32 sentences are not complete. Of the 97 sentences of unlucky former delinquents, only six do not result in incarceration and 34 are not complete. 
Table 4

Characteristics of Incarcerated and Released Former Delinquents

\begin{tabular}{|c|c|c|c|}
\hline & Nondelinquents & Unlucky Delinquents & Lucky Delinquents \\
\hline Days incarcerated & $492.0(438.8)$ & $847.9(621.3)$ & $401.6(318.8)$ \\
\hline \multicolumn{4}{|l|}{ Worst offense type (\%): } \\
\hline Drug & 63.3 & 45.6 & 75.3 \\
\hline Violent & 25.9 & 33.3 & 16.4 \\
\hline Property & 10.2 & 21.0 & 8.2 \\
\hline Worst offense score & $4.71 \quad(1.58)$ & $5.08 \quad(1.78)$ & $4.59 \quad(1.80)$ \\
\hline Delinquent points & N.A. & $1.28 \quad(.45)$ & $1.30 \quad(.46)$ \\
\hline Nondelinquent offender score & $3.55 \quad(2.08)$ & $4.70 \quad(1.73)$ & $4.60 \quad(2.18)$ \\
\hline Age at observation & $(1.76)$ & $(2.02)$ & $(1.32)$ \\
\hline Black (\%) & 80.5 & 68.4 & 80.8 \\
\hline Total arrests in window & 1.17 (2.98) & $1.30 \quad(2.44)$ & $1.38 \quad(3.35)$ \\
\hline Total charges in window & $.74 \quad(2.24)$ & $.79 \quad(1.41)$ & $.90 \quad(2.28)$ \\
\hline$N$ & 1,628 & 57 & 73 \\
\hline
\end{tabular}

Note. Standard deviations are shown in parentheses. N.A. = not applicable.

fense rates. I correct for the inexact mapping between arrests and offenses by multiplying the number of times an individual is arrested by the clearance rate for the arresting agency. ${ }^{28}$ This calculation is straightforward for index crimes. The clearance rate is the number of confirmed offenses known to a given agency in a particular year divided by the number of offenses cleared due to an arrest by that agency that year, as reported in the Uniform Crime Reports. ${ }^{29}$ However, this transformation is not possible for all other offenses, including drug offenses, kidnapping, arson, fraud, and alcohol-impaired driving. Because no measurement of drug offenses analogous to that in the Uniform Crime Reports exists, I report only the number of expected arrests on drug charges per person per year. ${ }^{30}$

\section{The Incapacitative Effect of Sentence Enhancements}

Table 5 presents my estimate of the average number of crimes prevented through incapacitation per person per year, on the basis of the number of times the 73 lucky former delinquents were arrested during their postrelease window. Just over 30 percent of the lucky former delinquents were arrested for a total 102 criminal acts while they otherwise would have remained incarcerated, and their offense rates suggest that incarcerating a former delinquent for 1 additional year prevents 2.8 arrests in that year. Of those arrests, the state files an average of two charges per year against former delinquents during that marginal year.

${ }^{28}$ Spelman (1994, p. 168) says there is "no dispute" over the use of this procedure.

${ }^{29}$ Table A3 displays these average clearance rates by index crime for law enforcement agencies nationwide and in Maryland. Nationwide, an average of 7.61 crimes are reported to police for every cleared offense, which is approximately equivalent to clearance rates in Maryland.

${ }^{30}$ Estimates by Abt Associates (2001) and Federal Bureau of Investigation (2009) imply that anywhere from 40 to 2,030 drug transactions occur per arrest for drug offenses. Thanks are due to Jonathan Caulkins for directing me to these national estimates and pointing out their limitations. 
Table 5

Crimes Averted through Incapacitation: Indicators of Mean Annual Crime Rates of 23-25-Year-Olds Released Early

\begin{tabular}{lcccccccr}
\hline & \multicolumn{2}{c}{$(1)$} & \multicolumn{2}{c}{$(2)$} & \multicolumn{2}{c}{$(3)$} & & $(4)$ \\
\hline Free days & 164 & $(9.46)$ & 151 & $(9.86)$ & 208 & $(13.5)$ & 113 & $(5.70)$ \\
Recidivism rate (\%) & 30.1 & $(.05)$ & 34.5 & $(.06)$ & 35.6 & $(.06)$ & 20.5 & $(.05)$ \\
Arrest rate & 2.79 & $(.72)$ & 3.09 & $(.83)$ & 2.67 & $(.65)$ & 2.66 & $(.73)$ \\
Prosecuted charge rate & 1.96 & $(.59)$ & 2.00 & $(.62)$ & 1.95 & $(.57)$ & 2.03 & $(.72)$ \\
Drug arrest rate & 1.65 & $(.52)$ & 1.98 & $(.67)$ & 1.52 & $(.44)$ & 1.63 & $(.68)$ \\
Implied index crime rate & 1.44 & $(.66)$ & 1.07 & $(.66)$ & 1.65 & $(.61)$ & 1.50 & $(.83)$ \\
Estimated social cost $(\$):$ & & & & & & & & \\
$\quad$ Arrests only & $16,111(8,555)$ & 15,182 & $(9,786)$ & 13,363 & $(6,920)$ & 12,549 & $(10,931)$ \\
Implied index crimes & $26,855(13,897)$ & $22,378(14,773)$ & $22,992(11,576)$ & $21,062(16,976)$ \\
\hline
\end{tabular}

Note. For columns 1, 3, and 4, $N=73$ offenders; $N=55$ drug offenders in column 2. Standard errors are in parentheses. Index crimes include murder, assault, rape, robbery, burglary, car theft, and larceny.

A large fraction of these offenses are drug offenses-1.6 drug arrests are made per person per year, roughly 57 percent of all charges. Applying crime- and agency-specific clearance rates to the nondrug arrests, the arrests accumulated by individuals suggest that 23-25-year-old unlucky former delinquents would have been involved in 1.4 index crimes per person per year had they not been incarcerated. ${ }^{31}$ An upper bound of offending behavior can be estimated by inflating the clearance-rate-adjusted estimates by the fraction of crimes reported to police-this increases the potential rate of crimes averted from 1.4 to 2.9 crimes per year. ${ }^{32}$ Lucky delinquents are arrested for a large number of violent crimes during their free time: 20 percent of the arrests accumulated are for assault or attempted murder, ${ }^{33} 4$ percent for arson, and 3 percent for weapons violations. Approximately 17 percent of arrests are for property and general crimes, such as car theft, conspiracy, trespassing, and uttering false statements to police. The pattern of recidivism suggests some degree of specialization in crime; individuals convicted of drug offenses (column 2) are arrested an average of 3.1 times per person per year, roughly equal to the mean arrest rate for the entire group, but appear to be less likely than average to be involved in index crimes, which implies that they are rearrested for drug offenses. Reestimating

${ }^{31}$ Of those individuals who recidivate, the mean number of arrests per person per year is 9.7, with 6.9 charges filed per person per year. Clearance rates suggest that individuals who are rearrested are probably involved in 5.2 index crimes per person per year. These estimates are notably similar to the "high-rate offender" rate of 7 offenses per person per year assumed by Greenwood et al. (1996).

${ }^{32}$ This estimate is produced by calculating the incident-weighted mean index crime-reporting rate for each index crime, excluding murder, as recorded in the National Crime Victimization Survey metropolitan statistical area (MSA) data between 2002 and 2004 (Bureau of Justice Statistics 2007). These reporting rates are based on a representative sample of crime reporting in the 30 largest MSAs, which include Baltimore and Prince George's County. The unweighted mean reporting rates in these Maryland jurisdictions are within 4 percentage points of the national rates, with the exception of robbery, where the reporting rate is 10 percentage points lower. Substituting the local robberyreporting rate for the national one does not affect my estimate.

${ }^{33}$ For cost-benefit purposes, I classify charges for attempted murder as assaults. 
these measures of criminal activity using the upper and lower bounds of a 95 percent confidence interval around my estimate of days incarcerated per point (columns 3 and 4) yields substantively the same results.

These estimates are an order of magnitude lower than those produced by previous studies of the incapacitation effect using individual-level data. Recall that existing estimates range from 187 to approximately 12 crimes averted per person per year. This striking difference highlights the contribution this paper makes to the literature on incapacitation. First, all of the previous studies base their estimates on samples of current prison or jail inmates, who may or may not be nearing release. In contrast, my study assesses the effect of incapacitation only on offenders who are about to be released. These offenders will, on average, be less criminal than the average inmate (Kuziemko 2007), whose behavior has been the focus of existing literature.

Second, previous studies often rely on past criminal behavior to create mean estimates of incapacitation. This practice creates samples in which all individuals have nonzero hypothetical offense rates by construction. Moreover, there are good reasons to believe that a given offender's criminal activity prior to incarceration is significantly higher than the criminal activity he would partake in if released early. ${ }^{34}$ In contrast, my estimates suggest that approximately two-thirds of individuals would not recidivate during the enhancement portion of their sentences.

Third, I present incapacitation estimates for a particular subset of the offending population. Although past estimates often break down the benefit of incapacitation by offense type, my estimates are averaged over all offense types, but my population is comparatively homogenous with respect to age. Although they are not necessarily at the end of their criminal careers, 23-25-year-olds, who are between the ages of 25 and 27 when released, are past their peak criminal years, which are generally agreed to be between 18 and 21 (Hirschi and Gottfredson 1983; Farrington 1986; Blumstein and Cohen 1987). For example, according to the Bureau of Justice Statistics, in 2005, 49 percent of homicides were committed by someone younger than 25 , a group that made up roughly 34 percent of the population. Because criminality decreases with age (Hirschi and Gottfredson 1983; Farrington 1986; Blumstein and Cohen 1987), one would expect the number of crimes averted through incapacitation to decline as the population being targeted ages.

Finally, it should be noted that past studies used data from the 1980s and 1990s, whereas my estimates are based on data from 2001 to 2005. If the decline in crime over the end of the twentieth century is due to individuals' committing less crime, as opposed to fewer individuals committing crime, the number of crimes averted through incapacitation in the twenty-first century should be reasonably assumed to be lower than in the twentieth century.

I estimate that 23-25-year-olds incarcerated for 1 additional year would likely

${ }^{34}$ This is one of Zimring and Hawkins (1995) critiques of "window-based" incapacitation estimates. 
have been arrested at a rate of approximately 2.8 times per year per person, if released early, and would have been prosecuted for two offenses. There are two important and potentially confounding issues that must be addressed in order to say that these crimes are averted through incapacitation: temporal displacement of crime and criminal replacement.

Consider a three-period model in which all offenders are incarcerated in period 1 , half of offenders are released at the beginning of period 2, and the rest are released at the beginning of period 3. If sentence enhancements cause only temporal displacements in crime rates, we would expect that, in period 3, unlucky offenders would have higher offending rates than those released earlier. It is possible to directly test for this possibility by comparing the number of charges accumulated by the 57 released unlucky delinquents to the 50 released lucky delinquents whom I observe two periods after being incarcerated. ${ }^{35}$ Using a negative binomial model to account for overdispersion in charges, ${ }^{36} \mathrm{I}$ find no evidence that unlucky delinquents offend at higher rates than the lucky delinquents after controlling for differences in criminal background, jurisdiction of release, age, and race.

A second threat to my incapacitation estimates is the issue of criminal replacement, which Ehrlich (1981) identifies in a seminal article on incarceration and crime ${ }^{37}$ The idea of criminal replacement is that some fraction of the crimes that would have been committed by incarcerated individuals are committed by nonincarcerated offenders. With regard to drug offenses and organized crime, criminal replacement is clearly observed. In fact, Caulkins et al. (1997) suggest that, in terms of reducing the total supply of illegal drugs, conducting a drug crackdown in which more arrests are made is a more effective policy than increasing the sentence of one drug offender. ${ }^{38} \mathrm{I}$ am unaware of empirical evidence of significant criminal replacement for other types of offenses. The existence of criminal replacement would cause me to overestimate the number of crimes prevented through incapacitation. My data do not allow me to test this phenomenon.

\section{The Social Welfare of Sentence Enhancements}

I find evidence that sentence enhancements do lower crime through incapacitation, although the marginal number of crimes averted by incapacitation

${ }^{35} \mathrm{I}$ do not observe any street time for 23 of the 73 released lucky delinquents after their sentence disenhancements expire.

${ }^{36}$ Results of this estimation are available by request and are discussed in detail in Owens (2007).

${ }^{37}$ An issue tangential to criminal replacement is co-offending. I have no way of knowing whether individuals in my data are arrested for offenses they commit with another person, but criminologists generally assume that co-offending rates are highest relative to total offending among juveniles. With an average postrelease age of 25 , I assume co-offending is not a large issue for my analysis.

${ }^{38}$ The intuition behind this finding is that arrests directly decrease the drug supply-that is, drugs are seized-whereas incarcerating a drug dealer only creates a possible opening for a new potential dealer. 
as a result of sentence enhancements is lower than the average number of crimes prevented by incarceration in general. To evaluate these incapacitative effects, it is useful to assign a monetary cost to criminal acts. This assignment allows a comparison of the social costs of reduced incapacitation and the fiscal costs associated with incarcerating an offender for an additional period. According to estimates derived in Miller, Cohen, and Wiersema (1996), the social cost of the crimes potentially prevented by incapacitation resulting from a 1-year sentence enhancement varies from a low estimate of $\$ 16,000$, if each arrest is assumed to represent one crime, to just under $\$ 27,000$, if each arrest is inflated by the appropriate clearance rates. More recent studies (Cohen et al. 2004; Rockoff and Linden 2006) have suggested that the social cost of crime may be significantly higher. Still, the estimates of Miller, Cohen, and Wiersema (1996) provide the most disaggregated estimates for the largest number of crimes and yield the most conservative dollar values.

How do these social costs compare to the additional cost to society of imposing longer sentences? I evaluate the dollar value of crimes averted through incapacitation against the fiscal cost of housing an additional state prisoner for an additional year in Maryland. Note that this evaluation excludes the additional social cost imposed on the families of inmates who receive longer sentences. Therefore, I ask the specific question, how large does the social cost of sentence enhancements have to be for them to decrease net welfare?

In 2004, the U.S. Department of Justice estimated that the average annual operating cost of a state prison nationwide was $\$ 24,032$ per inmate in 2005 dollars (Stephen 2004). Between 1989 and 2005, the state of Maryland spent approximately $\$ 23,748$ per inmate per year (Maryland 1990-2007). Past studies of incapacitation (DiIulio and Piehl 1991, 1995; Donohue and Siegelman 1998; Spelman 1994) evaluate the benefit of crimes averted against this average cost per prisoner. Average cost is an appropriate benchmark against which to evaluate the benefits of incapacitation only if the increase in state spending when a facility incarcerates its first prisoner is exactly the same as the increase in state spending when that facility incarcerates its 500th prisoner. This notion is unlikely to be true because of the high fixed costs of maintaining and operating a prison. If the prison population increases by one person, the state will have to provide an additional meal but not an additional cook.

In principle, the marginal cost of an additional prisoner approaches infinity after the institution reaches full capacity, but anecdotal evidence and the existence of prison-overcrowding legislation suggest that, operationally, corrections departments will make room for new prisoners. ${ }^{39}$ Before 2000, the Maryland state budget books reported official prison capacity as well as average daily population. According to these sources, Maryland state facilities were operating at or above

\footnotetext{
${ }^{39}$ In related work, Kuziemko and Levitt (2004) find that the increased number of prisoners convicted of drug offenses did result in the crowding out of inmates convicted of minor offenses, but the fraction of sentences served by offenders convicted of violent crimes or major property offenses was unchanged by increases in the inflow of inmates.
} 
capacity more than half of the time between fiscal years 1989 and 2000 (Maryland 1990-2007).

To estimate the marginal cost of housing a former delinquent for an additional year, I use a fixed-effects approach, where my identification is based on changes in inmate population and expenditure within a facility, not differences across facilities. I express total expenditure each year in a given facility as a function of the average daily population, including year and facility fixed effects, as well as dummy variables indicating that official capacity increased or decreased during that year. It is easy to think of omitted variables that are correlated with both population and expenditure, such as the age of the facility or the quality of the management, and a fixed-effects model allows me to avoid these sources of bias. I allow the marginal cost of an additional prisoner to vary according to whether there is a change in capacity and whether the prisoner is housed in a maximum, medium-, or minimum-security facility. Data on average daily population, total facility expenditure, and capacity for a total of 24 state-run institutions are taken from the Maryland state budget books (Maryland 1990-2007), which report actual values for fiscal years 1989-2005. The fiscal year 1993 is excluded because of missing data.

Estimates of the marginal cost of housing an additional prisoner are presented in Table 6. When I control for upgrades and downgrades in official capacity (column 3), increasing the average daily population by one person for 1 year requires an increase in spending of $\$ 11,350(t=5.54)$, less than half the average cost of incarceration per inmate. Not surprisingly, during years when the capacity of the facility increases, the marginal cost of an extra prisoner is about $\$ 1,000$ less. Housing an additional prisoner in a moderate-security facility (column 5 ) costs the state $\$ 13,030(t=5.29)$, approximately $\$ 8,000$ more than housing the additional prisoner in a minimum-security facility. To address concerns that the marginal cost of a prisoner is increasing in prison population, I included average daily population squared as a dependent variable. Surprisingly, I estimate the coefficient on this term to be negative, although small in magnitude and statistically insignificant.

I estimate the fiscal cost of incarcerating an additional offender for an additional year to be at most $\$ 13,800$, and in most years closer to $\$ 11,350$. This marginal cost is slightly more than half the annual expenditure per inmate. It is also roughly equivalent to the lower estimated social costs of crimes avoided per person per year through incapacitation in Table 5 . This finding suggests that increasing the sentence length of offenders between 23 and 25 years old may generate positive net benefits to society.

Recall that I do not attempt to quantify the social cost of an additional year of incarceration, such as a family's emotional distress. How large must these costs be to reverse this conclusion? The social cost of crimes averted through incapacitating a 23-25-year-old former delinquent are likely to fall between $\$ 12,500$ and $\$ 26,000$ a year. Depending on the security level of the facility and changes in that facility's official capacity, the fiscal cost of an additional year of 


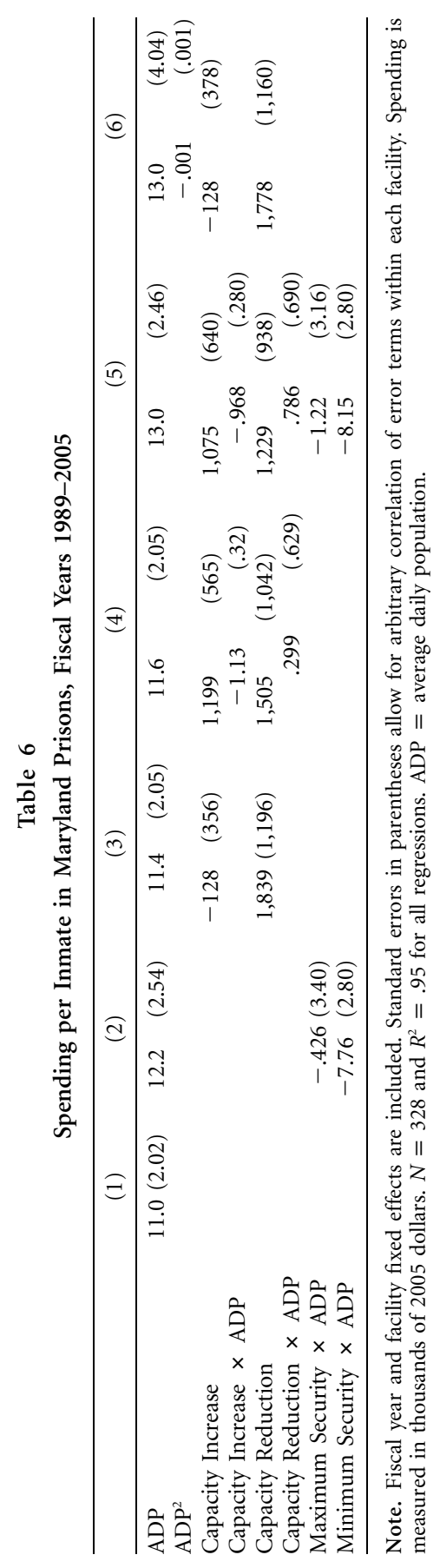


incarceration in Maryland ranges from $\$ 4,700$ to $\$ 13,800$ per person. In the most likely scenario, where the state spends $\$ 11,350$ per prisoner per year, the net benefit of sentence enhancements is between $\$ 1,150$ and $\$ 14,600$ per prisoner per year. In a worst-case scenario, where incarceration is extremely expensive, benefits range from a $\$ 1,300$ net loss to a $\$ 12,200$ gain. In a best-case scenario, the social costs of additional periods of incarceration must be more than $\$ 21,300$ per prisoner per year for the net benefit of sentence enhancements to be strictly negative.

\section{Conclusion}

Sentence enhancements reduce crime by deterring potential offenders from committing crimes and by preventing convicted offenders from reoffending through lengthened incapacitation. In this paper I focus on the latter effect. I use a change in Maryland sentencing law that eliminated juvenile history as a factor in the sentencing of 23-25-year-olds as a source of quasi-experimental variation in sentence length, which allows me to avoid bias due to nonrandom assignment of punishment. I estimate that incarcerated 23-25-year-old former delinquents are arrested at a rate of 2.8 times per person per year and are involved in 1.4-1.6 index crimes per person per year during their postrelease window of free time.

This estimate of crimes averted is much smaller but more precise than previous estimates of crimes avoided through incapacitation because I identify the additional benefit of incarcerating an offender for 1 additional year, whereas previous studies have tended to look at the average benefit of the entire incarcerated population. The large difference between my findings and past research highlights the importance of identifying the specific population affected by a policy change. This paper also fits in a series of recent papers reexamining the social benefits of prison during a time when crime rates are at historic lows and incarceration rates at equally striking highs (Sweeten and Apel 2007; Johnson and Raphael 2007).

My results are consistent with these recent papers in finding that, over time, the benefit of incapacitation has decreased. However, even though I find that the incapacitative benefits of sentence enhancements are perhaps smaller than previously thought, the social cost of the crimes that offender would otherwise commit during that 1-year period is higher than the fiscal cost of extending the sentence of an offender with an established criminal history. After controlling for facility upgrades and allowing the impact of additional prisoners to vary nonlinearly, I find that the cost to the state of holding a prisoner for an additional year is less than half of the average spending per inmate, which suggests a substantial fixed cost to operating a correctional facility. Although it is up to policy makers to decide whether anticipated changes in inmate population are large enough to make average cost the relevant metric in a more comprehensive 
cost-benefit analysis, the difference in costs is large enough to warrant consideration.

Given recent work that finds no negative labor market consequences associated with longer prison spells (Kling 2006; Cho and LaLonde 2005), it seems unlikely that the social costs associated with longer periods of incarceration would be large enough for sentence enhancements to fail a cost-benefit analysis. More work on the broader social costs of sentence enhancements is needed to substantiate this claim. However, my results suggest that only in the case in which additional incapacitation is the least beneficial and incarceration is the most expensive does the incapacitative effect of sentence enhancements fail to provide a positive net benefit to society.

\section{Appendix}

\section{Estimation Procedures}

\section{Incorporating Incomplete Sentences}

In 766 sentences, an individual enters prison or jail but is not released. Let $S_{i}^{c}$ be the length of the spell completed at the time when the sample was drawn. The relationship between the actual length and measured length is then

$$
S_{i}=\left\{\begin{array}{l}
S_{i}^{*} \text { if } S_{i}^{\star}<S_{i}^{c} \\
S_{i}^{c} \text { if } S_{i}^{c} \leqslant S_{i}^{\star}
\end{array}\right\},
$$

where $S^{i}=S_{i}^{*}$ if $S_{i}^{*}$ is greater than zero and the offender is released by the end of my sample. Let $d_{i}$ equal one if sentence $i$ is complete, and zero otherwise. The likelihood function is therefore

$$
L\left(\Lambda_{i}\right)=\sum\left\{d_{i} \ln \left[h\left(S_{i}, \Lambda_{i}\right)\right]+\left(1-d_{i}\right) \ln \left[1-H\left(S_{i}^{c}-1, \Lambda_{i}\right)\right]\right\},
$$

where $\Lambda_{i}$ represents the values of the independent variables associated with sentence $i, h\left(S_{i}, \Lambda_{i}\right)$, is the negative binomial probability density function evaluated at $S_{i}$, and $H\left(S_{i}^{c}-1, \Lambda_{i}\right)$ is the negative binomial cumulative density function evaluated at $S_{i}^{c}-1$.

\section{Estimation of Individual Sentence Enhancements}

Expected sentence length for any given conviction is equivalent to the expected number of days incarcerated multiplied by the probability that the sentence results in any incarceration:

$$
\begin{aligned}
& E\left(S_{i}^{*} \mid X_{i}\right) \\
& =\frac{\left.\exp _{[\omega}+\beta^{\mathrm{N}} \text { Facts }_{i}^{\mathrm{N}}+\theta_{\mathrm{OG}} \text { OldGuide }_{i}+\theta_{\mathrm{D}} D_{i}+\theta_{\mathrm{OGD}}\left(\text { OldGuide }_{i} \times D_{i}\right]\right]}{\delta} P\left(S_{i}^{\star}>0 \mid X_{i}\right),
\end{aligned}
$$


where

$$
\begin{aligned}
P\left(S_{i}^{*}>0 \mid X_{i}\right)= & \Phi\left[\varpi+\beta^{\mathrm{p}} \text { Facts }_{i}^{\mathrm{p}}+\alpha_{\mathrm{OG} \text { OldGuide }_{i}}\right. \\
& \left.+\alpha_{\mathrm{D}} D_{i}+\alpha_{\mathrm{OGD}}\left(\text { OldGuide }_{i} \times D_{i}\right)\right],
\end{aligned}
$$

where $\Phi(x)$ is the standard normal cumulative distribution function evaluated at $x$. The additional number of days per point that an offender with $k$ points would have been incarcerated after sentence $i$ is estimated to be

Enhancement ${ }_{i}^{k}$

$$
\begin{aligned}
& =\Phi\left[\hat{\beta}^{\mathrm{p}} \operatorname{Facts}_{i}^{\mathrm{p}}+\hat{\alpha}_{\mathrm{OG}} \text { OldGuide }_{i}+\hat{\alpha}_{\mathrm{D}} D_{i}+\hat{\alpha}_{\mathrm{OGD}}\left(\text { OldGuide }_{i} \times D_{i}\right)\right]\left(\frac{\Delta_{i}^{k}}{k}\right)
\end{aligned}
$$

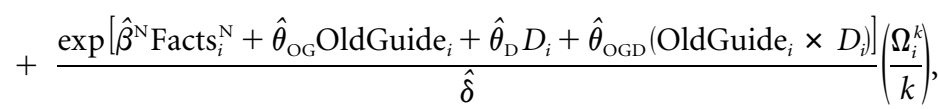

where

$$
\begin{aligned}
\Delta_{i}^{k}= & {\left[\frac{\exp \left(\hat{\beta}^{\mathrm{N}} \mathrm{Facts}_{i}^{\mathrm{N}}+\hat{\theta}_{\mathrm{OG}}+k \hat{\theta}_{\mathrm{D}}+k \hat{\theta}_{\mathrm{OGD}}\right)-\exp \left(\hat{\beta}^{\mathrm{N}} \mathrm{Facts}_{i}^{\mathrm{N}}+k \hat{\theta}_{\mathrm{D}}\right)}{\hat{\delta}}\right] } \\
& -\left[\frac{\exp \left(\hat{\beta}^{\mathrm{N}} \mathrm{Facts}_{i}^{\mathrm{N}}+\hat{\theta}_{\mathrm{OG}}\right)-\exp \left(\hat{\beta}^{\mathrm{N}} \mathrm{Facts}_{i}^{\mathrm{N}}\right)}{\hat{\delta}}\right]
\end{aligned}
$$

and

$$
\begin{aligned}
\Omega_{i}^{k}= & {\left[\Phi\left(\hat{\beta}^{\mathrm{P}} \operatorname{Facts}_{i}^{\mathrm{P}}+\hat{\alpha}_{\mathrm{OG}}+k \hat{\alpha}_{\mathrm{D}}+k \hat{\alpha}_{\mathrm{OGD}}\right)-\Phi\left(\hat{\beta}^{\mathrm{P}} \operatorname{Facts}_{i}^{\mathrm{P}}+k \hat{\alpha}_{\mathrm{D}}\right)\right] } \\
& -\left[\Phi\left(\hat{\beta}^{\mathrm{P}} \operatorname{Facts}_{i}^{\mathrm{P}}+\hat{\alpha}_{\mathrm{OG}}\right)-\Phi\left(\hat{\beta}^{\mathrm{P}} \operatorname{Facts}_{i}^{\mathrm{P}}\right)\right] .
\end{aligned}
$$

Two marginal effects are evaluated at each observation (one for each value of $k$ ), and each receives a weight equal to the fraction of delinquents who qualify for that number of points. The mean sentence disenhancement per point is the weighted mean of the marginal effects. 
Table A1

In-Sample and Out-of-Sample Sentences for 23-25-Year-Olds

\begin{tabular}{|c|c|c|c|c|c|c|}
\hline \multirow{2}{*}{ Sentence length (months) } & \multicolumn{2}{|c|}{ Final Sample } & \multicolumn{2}{|c|}{$\begin{array}{l}\text { Not Matched to } \\
\text { Arrest Records }\end{array}$} & \multicolumn{2}{|c|}{$\begin{array}{l}\text { Not Matched to } \\
\text { Incarceration Period }\end{array}$} \\
\hline & 61.2( & 200.60) & 20.22 & (64.73) & 4.89 & $(14.76)$ \\
\hline Incarcerated (\%) & 66.0 & & 48.6 & & 43.6 & \\
\hline Total charges & 1.52 & $(1.47)$ & 1.30 & $(.78)$ & 1.33 & $(.83)$ \\
\hline \multicolumn{7}{|l|}{ Worst offense type (\%): } \\
\hline Drug & 61.9 & & 59.4 & & 44.3 & \\
\hline Violent & 28.5 & & 27.7 & & 33.1 & \\
\hline Property & 9.1 & & 12.2 & & 20.9 & \\
\hline VOP & .48 & & .68 & & 1.63 & \\
\hline Worst offense score & 5.06 & (2.19) & 4.24 & $(1.84)$ & 3.53 & $(2.00)$ \\
\hline Delinquent points ${ }^{\mathrm{a}}$ & .09 & $(.34)$ & .03 & $(.21)$ & .05 & $(.27)$ \\
\hline Adult prior points ${ }^{\mathrm{a}}$ & 2.64 & $(1.76)$ & 1.84 & $(1.82)$ & 1.46 & $(1.50)$ \\
\hline Violation points $^{\mathrm{a}}$ & .32 & $(.47)$ & .21 & $(.41)$ & .19 & $(.39)$ \\
\hline Relationship points ${ }^{a}$ & .40 & (.49) & .26 & $(.44)$ & .24 & $(.42)$ \\
\hline Sentenced under old guidelines (\%) & 38.1 & & 35.9 & & 37.5 & \\
\hline Age at offense & 23.9 & $(.818)$ & 23.9 & $(.813)$ & 23.9 & $(.804)$ \\
\hline Black (\%) & 82.1 & & 72.2 & & 49.6 & \\
\hline Sentences & 3,345 & & 1,336 & & 1,166 & \\
\hline
\end{tabular}

Note. Standard deviations are in parentheses. VOP $=$ violation of parole. ${ }^{\text {a }}$ Used to calculate the offender score. 


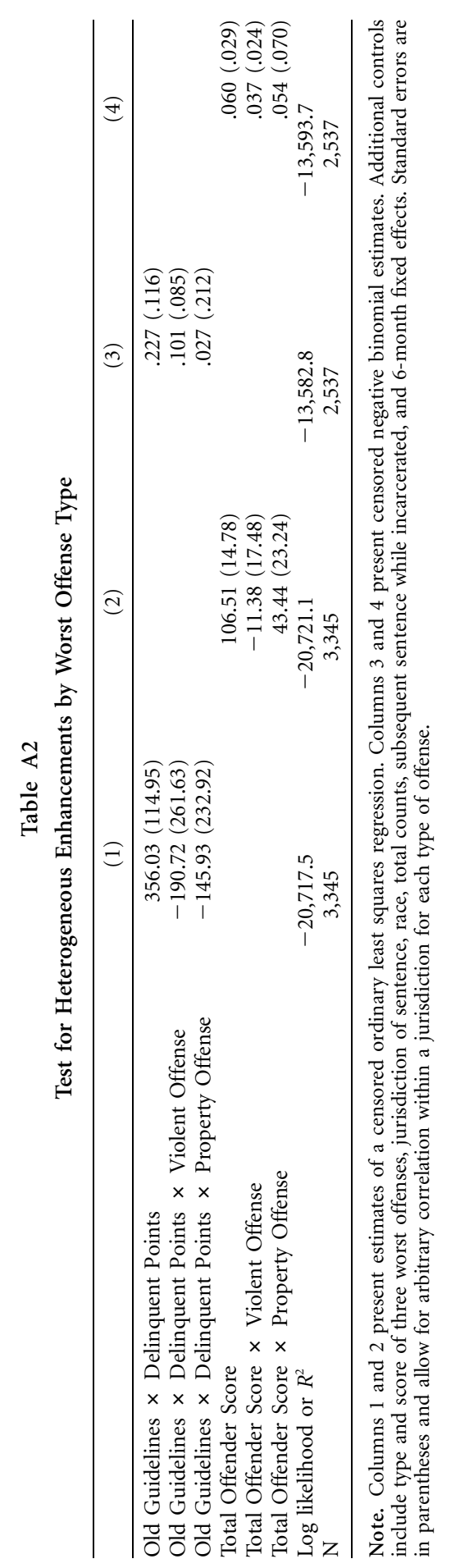


Table A3

Mean Number of Offenses per Arrest per Agency, 1999-2003

\begin{tabular}{|c|c|c|c|}
\hline & $\begin{array}{l}\text { National Average } \\
\text { (20,388 Agencies) }\end{array}$ & $\begin{array}{c}\text { Maryland } \\
\text { (185 Agencies) }\end{array}$ & $\begin{array}{c}\text { Baltimore City Police } \\
\text { Department }\end{array}$ \\
\hline Assault & $1.78 \quad(1.84)$ & $1.63 \quad(1.04)$ & $2.06(2.06)$ \\
\hline Murder & $1.28 \quad(.96)$ & $1.26 \quad(.85)$ & $1.56 \quad(.39)$ \\
\hline Rape & $2.39 \quad(2.57)$ & $1.86 \quad(1.29)$ & $2.76 \quad(.90)$ \\
\hline Robbery & $3.05 \quad(2.87)$ & $3.64 \quad(4.41)$ & $4.36 \quad(.62)$ \\
\hline Burglary & $9.44(12.10)$ & $7.16 \quad(6.63)$ & $6.43(1.34)$ \\
\hline Larceny & $10.07(17.26)$ & $9.08(14.72)$ & $7.42(1.92)$ \\
\hline Car Theft & $6.70(15.68)$ & $6.17(11.47)$ & $6.23(1.42)$ \\
\hline
\end{tabular}

Source. Author's calculations from Federal Bureau of Investigation (2001-5).

Note. Standard deviations are in parentheses.

\section{References}

Abt Associates. 2001. What American Users Spend on Illegal Drugs 1988-2000. Report No. NCJ 192334. Washington, D.C.: Office of National Drug Control Policy.

Ai, Chunrong, and Edward C. Norton. 2003. Interaction Terms in Logit and Probit Models. Economic Letters 80:123-29.

Avi-Itzhak, Benjamin, and Reuel Shinnar. 1973. Quantitative Models in Crime Control. Journal of Criminal Justice 1:185-217.

Becker, Gary S. 1968. Crime and Punishment: An Economic Approach. Journal of Political Economy 76:169-217.

. 1971. The Economics of Discrimination. Chicago: University of Chicago Press.

Bhati, Avi. 2007. Estimating the Number of Crimes Averted by Incapacitation: An Information Theoretic Approach. Journal of Quantitative Criminology 234:355-75.

Blumstein, Alfred. 1983. Incapacitation. Pp. 873-80 in volume 3 of Encyclopedia of Crime and Justice, edited by Sanfor H. Kadish. New York: The Free Press.

Blumstein, Alfred, and Jacqueline Cohen. 1987. Characterizing Criminal Careers. Science 237:985-91.

Bureau of Justice Statistics. 2007. National Crime Victimization Survey: MSA Data 1979-2004 (computer file). ICPSR Study No. 4576. Ann Arbor, Mich.: Inter-university Consortium for Political and Social Research.

Caulkins, Jonathan P. C., Peter Rydell, William L. Schwabe, and James Chiesa. 1997. Mandatory Minimum Drug Sentences: Throwing Away the Key or the Taxpayers' Money? Santa Monica, Calif.: RAND.

Cavanagh, David P., and Mark A. R. Kleiman. 1990. A Cost Benefit Analysis of Prison Cell Construction and Alternative Sanctions. Report prepared for the National Institute of Justice. Cambridge, Mass.: BOTEC Analysis Corporation.

Cho, Rosa, and Robert LaLonde. 2005. The Impact of Incarceration in State Prison on the Employment Prospects of Women. IZA Discussion Paper No. 1792. Institute for the Study of Labor, Bonn.

Cohen, Jacqueline. 1983. Incapacitation as a Strategy for Crime Control: Possibilities and Pitfalls. Crime and Justice 5:1-84.

Cohen, Mark A., Roland Rust, Sara Steen, and Simon Tidd. 2004. Willingness-to-Pay for Crime Control Programs. Criminology 421:86-106. 
DiIulio, John. 1996. Help Wanted: Economists, Crime, and Public Policy. Journal of Economic Perspectives 10(1):3-24.

DiIulio, John, and Anne M. Piehl. 1991. Does Prison Pay? The Stormy National Debate over the Cost-Effectiveness of Imprisonment. Brookings Review 9:28-35. . 1995. Does Prison Pay? Revisited. Brookings Review 13:20-25.

Donohue, John J., III, and Peter Siegelman. 1998., Allocating Resources among Prisons and Social Programs in the Battle against Crime. Journal of Legal Studies 27:1-43.

Doob, Anthony N., and Cheryl M. Webster. 2003. Sentence Severity and Crime: Accepting the Null Hypothesis. Crime and Justice 30:143-95.

Ehrlich, Isaac. 1981. On the Usefulness of Controlling Individuals: An Economic Analysis of Rehabilitation, Incapacitation and Deterrence. American Economic Review 713: $307-22$.

Farrington, David. 1986. Age and Crime. Crime and Justice 7:189-250.

Federal Bureau of Investigation. 2001-5. Uniform Crime Reporting Program Data [United States]: Offenses Known and Clearances by Arrest (computer files). ICPSR Study Nos. 3158, 3447, 3723, 4008, and 4124. Ann Arbor, Mich.: Inter-university Consortium for Political and Social Research.

. 2009. Uniform Crime Reporting Program Data [United States]: Arrests by Age, Sex, and Race, Summarized Yearly, 2001 (computer file). ICPSR Study No. 3792. Ann Arbor, Mich.: Inter-university Consortium for Political and Social Research.

Greenwood, Peter, C., Peter Rydell, Allan F. Abrahamse, Jonathan P. Caulkins, James Chiesa, Karyn Model, and Stephen P. Klein. 1996. Estimated Benefits and Costs of California's New Mandatory-Sentencing Law. Pp. 53-89 in Three Strikes and You're Out: Vengeance as Public Policy, edited by David Shichor and Dale K. Sechrest. Thousand Oaks, Calif.: Sage.

Hirschi, Travis, and Michael Gottfredson. 1983. Age and the Explanation of Crime. American Journal of Sociology 89:552-84.

Johnson, Rucker, and Steven Raphael. 2007. How Much Crime Reduction Does the Marginal Prisoner Buy? Working paper. University of California, Goldman School of Public Policy, Berkeley.

- 2009. The Effects of Male Incarceration Dynamics on AIDS Infection Rates among African-American Women and Men. Journal of Law and Economics 52:25-93.

Kling, Jeffrey. 2006. Incarceration Length, Employment, and Earnings. American Economic Review 96:863-76.

Kuziemko, Ilyana. 2007. Going off Parole: How the Elimination of Discretionary Prison Release Affects the Social Cost of Crime. NBER Working Paper No. 13380. National Bureau of Economic Research, Cambridge, Mass.

Kuziemko, Ilyana, and Steven Levitt. 2004. An Empirical Analysis of Imprisoning Drug Offenders. Journal of Public Economics 88:2043-66.

Lee, David, and Justin McCrary. 2006. Crime, Punishment, and Myopia. NBER Working Paper No. 11491. National Bureau of Economic Research, Cambridge, Mass.

Levitt, Steven. 2001. Deterrence. Pp. 435-50 in Crime, edited by James Q. Wilson and Joan Petersilia. San Francisco: ICS Press.

Maryland. 1990-2007. Department of Budget and Management. Operating Budget. Vol. 2. Baltimore: Department of Budget and Managment.

Miller, Ted R., Mark A. Cohen, and Brian Wiersema. 1996. Victim Costs and Consequences: A New Look. Research Report No. NCJ 155282. Washington, D.C.: U.S. Department of Justice. 
Nagin, Daniel. 1998. Deterrence and Incapacitation. Pp. 345-68 in The Oxford Handbook of Crime and Punishment, edited by Michael Tonry. New York: Oxford University Press.

Oliver, Pamela, Gary Sandefur, Jessica Jakubowski, and James E. Yocom. 2006. The Effect of Black Male Imprisonment on Black Child Poverty. Unpublished manuscript. Department of Sociology, University of Wisconsin, Madison.

Owens, Emily G. 2007. Government Regulation of Illicit Behavior. Ph.D. dissertation. University of Maryland, Department of Economics, College Park.

Pager, Devah. 2003. The Mark of a Criminal Record. American Journal of Sociology 108: 937-75.

Rockoff, Jonah, and Leigh Linden. 2006. There Goes the Neighborhood? Estimates of the Impact of Crime Risk on Property Values from Megan's Laws. NBER Working Paper No. 12253. National Bureau of Economic Research, Cambridge, Mass.

Shinnar, Shlomo, and Reuel Shinnar. 1975. The Effects of the Criminal Justice System on the Control of Crime: A Quantitative Approach. Law and Society Review 9:581-612.

Simborg, Donald. 1981. DRG Creep: A New Hospital-Acquired Disease. New England Journal of Medicine 304:1602-4.

Spelman, William. 1994. Criminal Incapacitation. New York: Plenum Press.

2000. What Recent Studies Do and Don't Tell Us about Imprisonment and Crime. Crime and Justice 27:419-94.

Stephen, James J. 2004. State Prison Expenditures, 2001. Special Report No. NCJ 202949. Washington, D.C.: U.S. Department of Justice.

Sweeten, Gary, and Robert Apel. 2007. Incapacitation: Revisiting an Old Question with a New Method and New Data. Journal of Quantitative Criminology 234:303-26.

Zedlewski, Edwin. 1987. Making Confinement Decisions. Report No. NCJ 105834. Washington, D.C.: National Institute of Justice.

Zimring, Frank, and Gordon Hawkins. 1995. Incapacitation: Penal Confinement and the Restrain of Crime. New York: Oxford University Press. 